\title{
Article \\ High Density Resistive Array Readout System for Wearable Electronics
}

\author{
Shanthala Lakshminarayana (D), Younghun Park (D), Hyusim Park *(iD) and Sungyong Jung *(D)
}

Citation: Lakshminarayana, S.; Park, Y.; Park, H.; Jung, S. High Density Resistive Array Readout System for Wearable Electronics. Sensors 2022, 22, 1878. https://doi.org/10.3390/ s22051878

Academic Editor: Roozbeh Ghaffari

Received: 26 January 2022

Accepted: 25 February 2022

Published: 27 February 2022

Publisher's Note: MDPI stays neutral with regard to jurisdictional claims in published maps and institutional affiliations.

Copyright: (C) 2022 by the authors. Licensee MDPI, Basel, Switzerland. This article is an open access article distributed under the terms and conditions of the Creative Commons Attribution (CC BY) license (https:// creativecommons.org/licenses/by/ $4.0 /)$.

\author{
Department of Electrical Engineering, University of Texas at Arlington, Arlington, TX 76019, USA; \\ shanthala.lakshminarayana@mavs.uta.edu (S.L.); younghun.park@mavs.uta.edu (Y.P.) \\ * Correspondence: hyusim.park@uta.edu (H.P.); jung@uta.edu (S.J.)
}

\begin{abstract}
This work presents a wearable sensing system for high-density resistive array readout. The system comprising readout electronics for a high-density resistive sensor array and a rechargeable battery, was realized in a wristband. The analyzed data with the proposed system can be visualized using a custom graphical user interface (GUI) developed in a personal computer (PC) through a universal serial bus (USB) and using an Android app in smartphones via Bluetooth Low Energy (BLE), respectively. The readout electronics were implemented on a printed circuit board (PCB) and had a compact dimension of $3 \mathrm{~cm} \times 3 \mathrm{~cm}$. It was designed to measure the resistive sensor with a dynamic range of $1 \mathrm{~K} \Omega-1 \mathrm{M} \Omega$ and detect a $0.1 \%$ change of the base resistance. The system operated at a $5 \mathrm{~V}$ supply voltage, and the overall system power consumption was $95 \mathrm{~mW}$. The readout circuit employed a resistance-to-voltage $(\mathrm{R}-\mathrm{V})$ conversion topology using a 16-bit analogto-digital converter (ADC), integrated in the Cypress Programmable System-on-Chip (PSoC ${ }^{\circledR}$ ) 5LP microcontroller. The device behaves as a universal-type sensing system that can be interfaced with a wide variety of resistive sensors, including chemiresistors, piezoresistors, and thermoelectric sensors, whose resistance variations fall in the target measurement range of $1 \mathrm{~K} \Omega-1 \mathrm{M} \Omega$. The system performance was tested with a 60-resistor array and showed a satisfactory accuracy, with a worst-case error rate up to $2.5 \%$. The developed sensing system shows promising results for applications in the field of the Internet of things (IoT), point-of-care testing (PoCT), and low-cost wearable devices.
\end{abstract}

Keywords: wearable; flexible; embedded system; high-density resistive array; Bluetooth Low Energy; point-of-care testing; electronic nose (e-nose); electronic skin (e-skin); wireless sensor network

\section{Introduction}

Wearable device technologies have been widely used in various head-to-toe applications such as environmental analysis, biomedical, physical, and physiological monitoring, primarily as accessory-type such as gloves, headsets, watches, wristbands, and textiles [1-5]. In current years, wearable systems with unique sensing materials and device structures have proved to be highly sensitive in mimicking the human olfactory system and tracking biophysical and biochemical signals, including skin temperatures, body movements, heart rates, pulse oximetry, blood pressures, breathing, wound healing, as well as continuous biofluid monitoring, for instance, sweat and interstitial fluids. In most cases, accessorytype wearable devices fail to provide an accurate electrode-based physiological detection capability due to unreliable body contact. Therefore, many recent research interests have moved to attachable body devices, including patch and sticker type devices [6-10]. Flexible sensing electrodes are required to implement these attachable devices, and modules should be miniaturized to provide comfortable body wearing. The use of flexible sensor arrays in point-of-care testing ( $\mathrm{PoCT}$ ) has been regarded as a promising approach to monitoring patients out of the hospital and lessening the burden on public healthcare systems in caring for older adults or patients with chronic diseases [11,12].

One of the most popular sensors for a wearable device is a resistive sensor, which has a sensing element whose resistance changes as a function of the target physical or 
chemical quantity. It is utilized in industrial, scientific, and commercial applications for sensing numerous physical parameters including, but not limited to, ambient temperature, humidity, pressure, strain/force, light intensity, and displacement [13-15]. Recent growth in the metal oxide (MOx) semiconductor sensor has enhanced the use of resistive sensors for more sophisticated applications such as chemical sensing, gas sensing, and biosensing [16-19]. Many resistive sensing materials, such as conductive polymers, nanomaterials that cover single- or multi-wall carbon nanotubes, graphene, and nanoparticles, can be deposited on flexible polyethylene terephthalate (PET) and polyimide-based substrates using inkjet or screen-printing techniques [20-22]. An array form of the flexible resistive sensor is developed and adopted in wearable electronic applications, which can help improve the measurement accuracy, sensitivity, and selectivity while helping in multianalyte detection [11,23-30]. Significant evolutions are engineered in readout electronics for sensing devices parallel to the sensor development. Nowadays, the demand for a modern integrated sensing system is growing that can combine analog or digital sensors, signal conditioning circuits, processing units, and communication interfaces in a single device [31-33]. The integrated sensing systems are often equipped with wireless interfaces using a standardized protocol such as Bluetooth Low Energy (BLE), Zigbee, Wi-Fi, LoRa, and Sigfox, enabling them to build wireless sensor networks for the Internet of things (IoT) applications.

Herein, we report the development of a wearable universal-type sensing system comprising miniaturized wireless readout electronics packaged into a wristband form factor. The readout is compatible with any custom or commercial resistive sensor array on a flexible substrate. Based on the type of materials deposited on the sensing array, the system can behave as a universal-type multi-functional sensing system, since it supports different resistive sensors, including chemiresistive, piezoresistive, thermo-electric, and their hybrid. The device can act as a resistive electronic skin (e-skin) for body temperature and blood pressure monitoring, a portable electronic nose (e-nose) for environmental harmful/toxic gas detection, and a comprehensive breathing analyzer. Compared with existing wearable resistive readout devices, the proposed device demonstrated the lowest circuit complexity on a microcontroller-based wearable platform and a high-density sensor array capacity. Thus, it could be an ideal solution for various applications such as wearable wireless sensor networks, PoCT, and battery-powered wireless telemetry for biomedical applications, while presenting a reference for designing low-complexity, low-cost, lowpower wearable systems for resistive sensor arrays. The device also supports a wide range of the resistance measurement from $1 \mathrm{~K} \Omega$ to $1 \mathrm{M} \Omega$, while providing a better tradeoff between the measurement accuracy and the processing speed. The rest of this paper is organized as follows. Section 2 describes the system-level specifications and the architecture of the proposed prototype. Section 3 shows the experimental results and the case analysis with a force-sensitive resistor as proof of concept. Finally, discussions and conclusions are drawn in Section 4.

\section{System Description and Specification}

The wearable system consists of the following modules: (1) a flexible customized or commercial resistive sensor array to detect target analytes such as biomarkers and chemicals; (2) a readout board to collect, process and transmit sensor data to a personal computer (PC) or a smartphone; and (3) a user-friendly graphical user interface (GUI) to control the device and display the obtained data, as shown in Figure 1. The hardware comprising readout electronics and a battery was housed in a wristband chassis. The system and the sensor array specifications targeted in this work are tabulated in Table 1. The resistance range of the piezoresistive and thermoelectric sensor varied from a few ohms to kiloohms [2,11], whereas the chemiresistive sensor varied up to a few megaohms [23]. Thus, an input resistance range of $1 \mathrm{~K} \Omega-1 \mathrm{M} \Omega$ was targeted in this work to cover a variety of resistive sensors. 


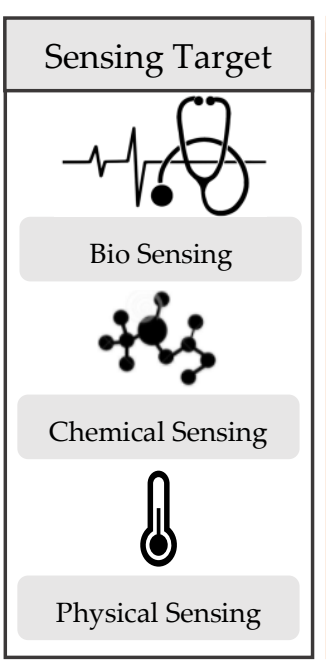

Commercial Flexible Sensor
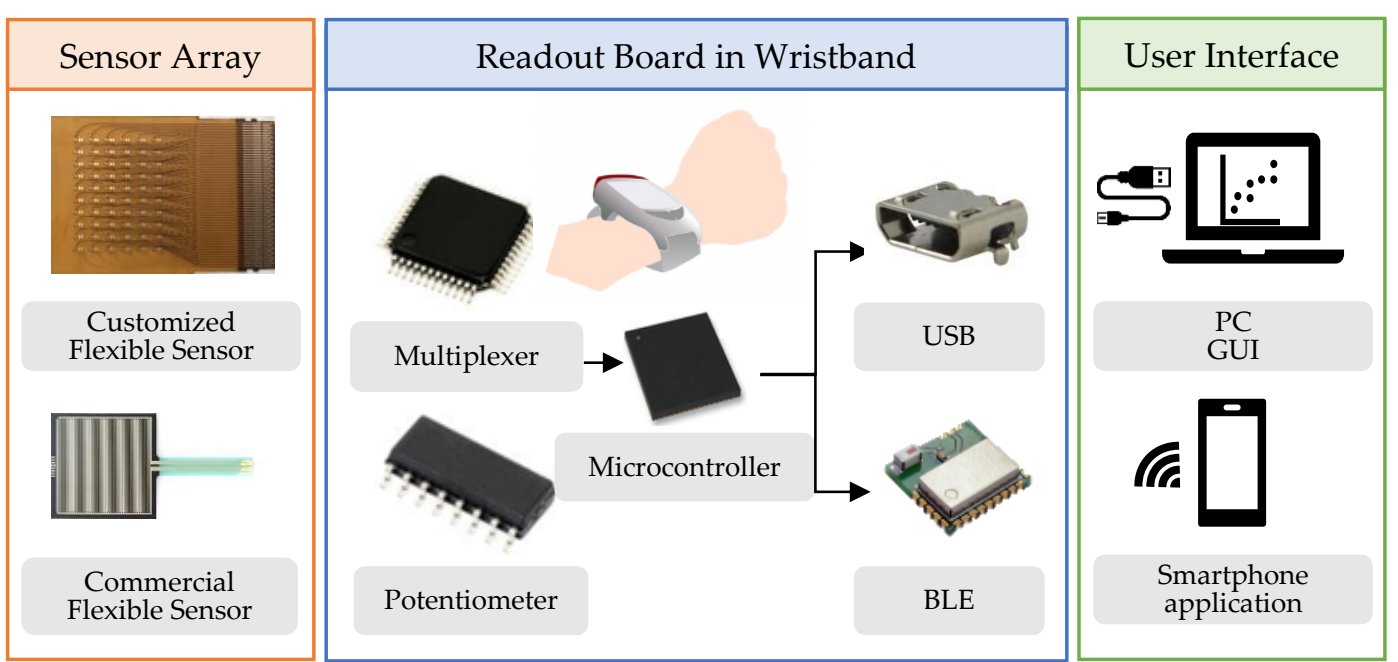

Figure 1. System-level block diagram, conceptually depicting readout electronics housed in a wristband chassis.

Table 1. System specifications.

\begin{tabular}{cc}
\hline Sensor Type & Resistive sensor \\
\hline Sensor resistance range & $1 \mathrm{~K} \Omega-1 \mathrm{M} \Omega$ \\
\hline Number of sensors & $60 ;$ can be expandable \\
\hline Sensor sensitivity & $0.1 \%$ \\
\hline Target processing time & $\sim 1 \mathrm{~s}$ \\
\hline Target applications & $\begin{array}{c}\text { Electronic skin (e-skin) for blood pressure and body } \\
\text { temperature monitoring; electronic nose (e-nose) for } \\
\text { environmental harmful/toxic gas detection }\end{array}$ \\
\hline
\end{tabular}

\subsection{Readout Board}

A readout board was required to measure the resistance change of the sensor as a function of the target physical or chemical reaction. A resistance-to-voltage $(\mathrm{R}-\mathrm{V})$ conversion was employed in the proposed readout circuit using a voltage divider concept consisting of a target resistive sensor $\left(R_{\text {sensor }}\right)$ and a reference resistor $\left(R_{r e f}\right)$. The function of the readout board involved the following: (1) collecting and multiplexing the sensor output, which was the voltage divider output; (2) processing the collected sensor output and then converting it to the digital form using an analog-to-digital converter (ADC); and (3) sending the converted digitalized data to a PC or smartphone using wired or wireless communication. The subsystems of the readout board were as follows: (1) multiplexers (MUX); (2) a digital potentiometer (DPOT); (3) a microcontroller unit (MCU); (4) a micro-universal serial bus (USB); (5) a Bluetooth unit; and (6) a power management circuit consisting of voltage regulators and a battery management circuit, as illustrated in Figure 2. The readout circuit was fabricated on one top and one bottom printed circuit boards (PCBs). The top PCB contained the MUX and the DPOT, whereas the bottom PCB consisted of the MCU, the BLE unit, and the power management block. 


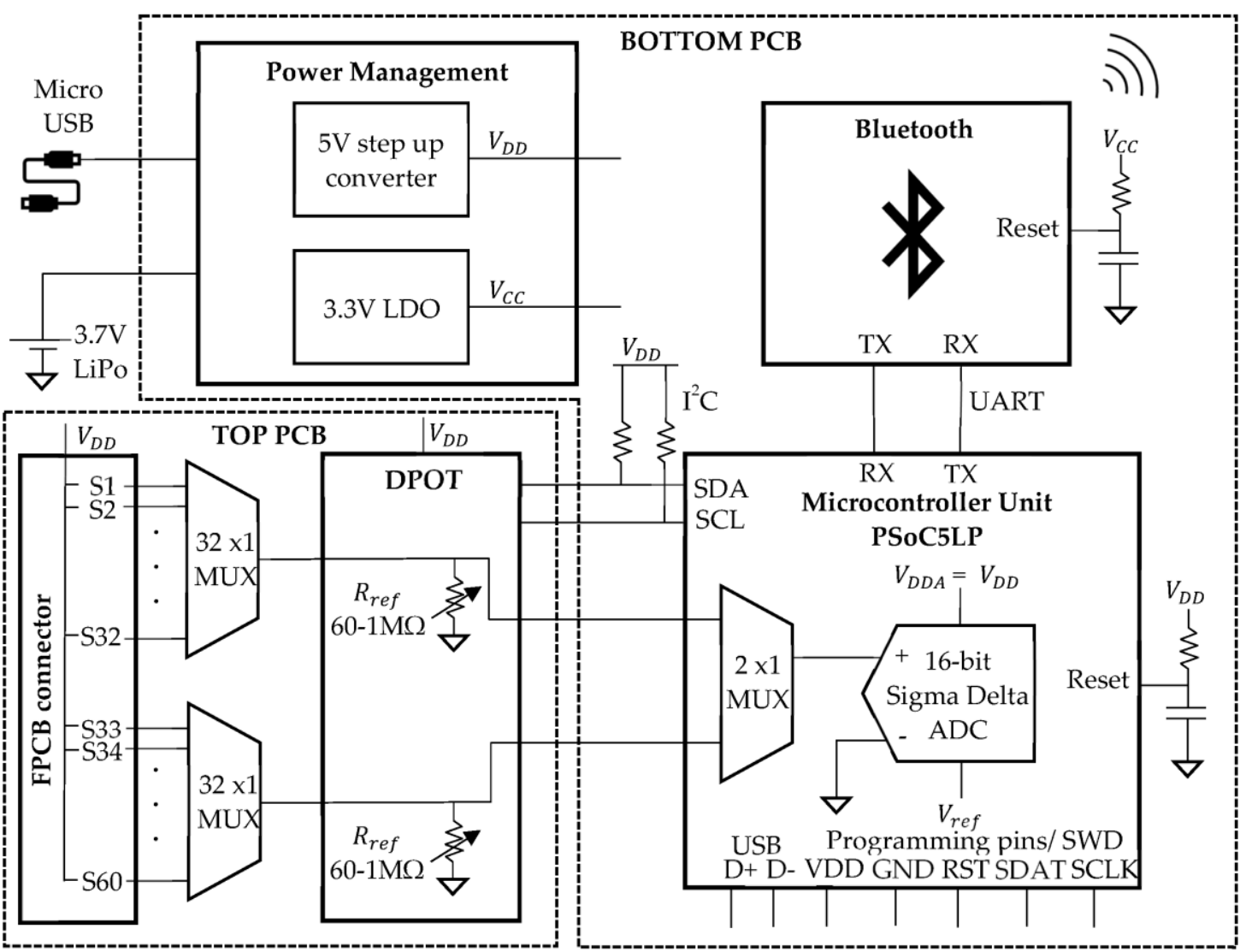

Figure 2. Detailed block diagram of the readout board.

\subsubsection{Top PCB Electronics}

S1-S60 in Figure 2 represents the 60 two-electrode resistive sensors connected to the readout board via a flexible PCB (FPCB) connector "FH29B-120S-0.2SHW(05)" (HiroseConnector, Kanagawa, Japan). One electrode of each resistive sensor was connected to the supply voltage $\left(V_{D D}\right)$ provided by the power management block of the readout board, while the other electrode of each sensor was connected to the multiplexer input. To individually address the 60 different sensors, two $32 \times 1$ MUX "ADG732BSUZ" (Analog Device, Norwood, MA, USA) were utilized. Due to the broad resistance range of the target sensor $(1 \mathrm{~K} \Omega-1 \mathrm{M} \Omega)$, using a fixed value of $R_{r e f}$ in the voltage divider circuit resulted in a voltage saturation at the ADC input, especially for the sensors that fell in the extreme corners of the target resistance range. To avoid this problem, the $R_{\text {ref }}$ value was tuned similar to the $R_{\text {sensor }}$ value using a dual-channel 8-bit DPOT "AD5242BRZ1M" (Analog Device, Norwood, USA). The resistance value of the DPOT $\left(R_{r e f}\right)$ can be varied from $60 \Omega$ to $1 \mathrm{M} \Omega$ by programming the registers. The DPOT had three terminals: $\mathrm{A}, \mathrm{B}$, and wiper. The wiper position of the DPOT was programmed by the Inter-Integrated Circuit $\left(\mathrm{I}^{2} \mathrm{C}\right)$ protocol and can be set to 256 distinct positions. Corresponding to the wiper position, the $R_{r e f}$ of the readout system can be set and calculated using Equation (1):

$$
R_{r e f}=R_{W A}(\mathrm{D})=\frac{256}{256-D} \times R_{A B}+R_{W},
$$

where $R_{W A}$ is the resistance between the DPOT " $\mathrm{A}$ " terminal and the wiper terminal, $\mathrm{D}$ is the decimal equivalent of the binary code between 0 and 255 which is loaded in the 8-bit register, $R_{A B}$ is the nominal end-to-end resistance and equals to $1 \mathrm{M} \Omega$, and $R_{W}$ is the wiper resistance contributed by the ON-resistance of the internal switch and equals to $60 \Omega$. 


\subsubsection{Bottom PCB Electronics}

The sensor data collected from the top PCB was sent to a MCU "CY8C5888LTILP097" (Cypress Semiconductors, San Jose, USA), also called PSoC5LP, on the bottom PCB. The PSoC5LP family provides a combination of a 32-bit Arm ${ }^{\circledR}$ Cortex ${ }^{\circledR}-\mathrm{M} 3$ processor with a flexible, configurable block of an analog subsystem, digital subsystem, routing, and general purpose input/outputs (GPIOs), which enables a high level of integration in a wide variety of applications. The analog multiplexer output was digitalized using an internal PSoC5LP 16-bit ADC operated in the single-ended mode with a rail-to-rail output. Once the digitalized ADC output $\left(A D C_{\text {voltage }}\right)$ was obtained, the unknown value of $R_{\text {sensor }}$ can be calculated using Equation (2):

$$
R_{\text {sensor }}=\frac{R_{\text {ref }} \times\left(V_{D D}-A D C_{\text {voltage }}\right)}{A D C_{\text {voltage }}} .
$$

where $R_{\text {sensor }}$ is the unknown sensor resistance, $R_{\text {ref }}$ is the reference DPOT resistance, $V_{D D}$ is the supply voltage, and $A D C_{\text {voltage }}$ is the digitalized ADC output. The ADC step corresponded to $76 \mu \mathrm{V}$, which could detect a $0.1 \%$ variation of the sensor output with a resistance range between $1 \mathrm{~K} \Omega$ and $1 \mathrm{M} \Omega$ (i.e., $1 \Omega$ change for the $1 \mathrm{~K} \Omega$ base sensor resistance and $1 \mathrm{~K} \Omega$ change for the $1 \mathrm{M} \Omega$ base sensor resistance). The readout board was designed to operate at a $V_{D D}$ of $5 \mathrm{~V}$. The power could be provided to the board by using a USB cable or a rechargeable battery. A $3.7 \mathrm{~V}$ and $500 \mathrm{mAh}$ lithium-ion polymer battery (LiPo) was employed in the prototype, which fit the $3 \mathrm{~cm} \times 3 \mathrm{~cm}$ wristband chassis. To provide a constant $5 \mathrm{~V}$ supply, a step-up/boost converter "TPS61240IDRVRQ1" (Texas Instruments, Dallas, USA) was adopted. A low-dropout (LDO) voltage regulator "TLV75733PDBVR" (Texas Instruments, Dallas, USA) was selected to provide a constant voltage $V_{C C}$ of $3.3 \mathrm{~V}$ to the BLE technology. The processed information was transferred to the user's smartphone via a BLE unit "SPBTLE-1S" (STMicroelectronics, Geneva, Switzerland). The BLE unit was interfaced with the MCU through the Universal Asynchronous Receiver/Transmitter (UART) protocol at a baud rate of 115,200 bits per second. The board also included a type B micro-USB “UJ2-MIBH2-4-SMT-TR” (CUI device, Lake Oswego, OR, USA), which powered the system and communicated with a PC using USB 2.0 standards. The detailed specifications of the components considered during the design are listed in Table 2.

Table 2. Component specifications considered for the top and bottom PCBs designs.

\begin{tabular}{lccc}
\hline Parameter & Value & Unit \\
\hline Operating supply voltage & ADG732BSUZ specifications & \\
\hline Supply current & $1.8-5.5$ & $\mathrm{~V}$ \\
\hline ON-resistance & 20 & $\mu \mathrm{A}$ \\
\hline & AD5242BRZ1M specifications & $\Omega$ \\
\hline Operating supply voltage & & $2.7-5.5$ & \\
\hline Supply current & & 100 & $\mathrm{~V}$ \\
\hline Digital potentiometer (DPOT) resistance range & $60-1 \mathrm{M}$ & $\mathrm{nA}$ \\
\hline
\end{tabular}


Table 2. Cont.

\begin{tabular}{|c|c|c|}
\hline Parameter & Value & Unit \\
\hline \multicolumn{3}{|c|}{ PSoC5LP specifications } \\
\hline Operating supply voltage & $1.71-5.5$ & $\mathrm{~V}$ \\
\hline Supply current at $6 \mathrm{MHz}$ & 3.1 & $\mathrm{~mA}$ \\
\hline Supply current at $24 \mathrm{MHz}$ & 8.9 & $\mathrm{~mA}$ \\
\hline Supply current in the sleep mode & 2 & $\mu \mathrm{A}$ \\
\hline Internal analog-to-digital converter (ADC) input range & $0-5$ & $\mathrm{~V}$ \\
\hline Internal ADC reference voltage $\left(\mathrm{V}_{r e f}=\mathrm{V}_{D D A} / 4\right)$ & 1.25 & $\mathrm{~V}$ \\
\hline Internal $\mathrm{ADC}$ conversion rate & 10 & KSPS \\
\hline \multicolumn{3}{|c|}{ TPS61240IDRVRQ1 specifications } \\
\hline Output voltage & $5 \pm 2 \%$ & $\mathrm{~V}$ \\
\hline Input voltage range & $2.3-5.5$ & $\mathrm{~V}$ \\
\hline Supply current & 30 & $\mu \mathrm{A}$ \\
\hline Output current & 450 & $\mathrm{~mA}$ \\
\hline \multicolumn{3}{|c|}{ TLV75733PDBVR specifications } \\
\hline Output voltage & $3.3 \pm 1 \%$ & $\mathrm{~V}$ \\
\hline Input voltage range & $1.45-5.5$ & $\mathrm{~V}$ \\
\hline Supply current & 25 & $\mu \mathrm{A}$ \\
\hline Output current & 1 & A \\
\hline \multicolumn{3}{|c|}{ SPBTLE-1S specifications } \\
\hline Operating supply voltage & $1.7-3.6$ & $\mathrm{~V}$ \\
\hline Bluetooth version & $\mathrm{v} 4.2$ & NA \\
\hline Radiated transmit power & +4 & $\mathrm{dBm}$ \\
\hline Receiver sensitivity & -84 & $\mathrm{dBm}$ \\
\hline Antenna frequency & $2402-2480$ & $\mathrm{MHz}$ \\
\hline Supply current while receiving & 7.7 & $\mathrm{~mA}$ \\
\hline Supply current while transmitting at $5 \mathrm{dBm}$ & 15 & $\mathrm{~mA}$ \\
\hline Supply current while transmitting at $0 \mathrm{dBm}$ & 11 & $\mathrm{~mA}$ \\
\hline Supply current while in the sleep mode & 0.9 & $\mu \mathrm{A}$ \\
\hline
\end{tabular}

The photos of the assembled top and bottom PCBs are shown in Figure 3. The small form factor is an essential criterion to make the device suitable for wearable applications. To obtain a small form factor, two $0.2 \mathrm{~mm}$ thick PCBs were designed to stack them back-toback, instead of designing the readout circuit on a single large PCB. Two two-layered PCBs were preferred as a substitute for a four-layered PCB to reduce the fabrication cost. Both the dimensions of the top and bottom PCBs were $3 \mathrm{~cm} \times 3 \mathrm{~cm}$, making the device suitable for wearing as a wristband. The "Eagle 9.4.2" software (Autodesk, San Rafael, CA, USA) was used to design the layout of the two-layer readout PCBs. 


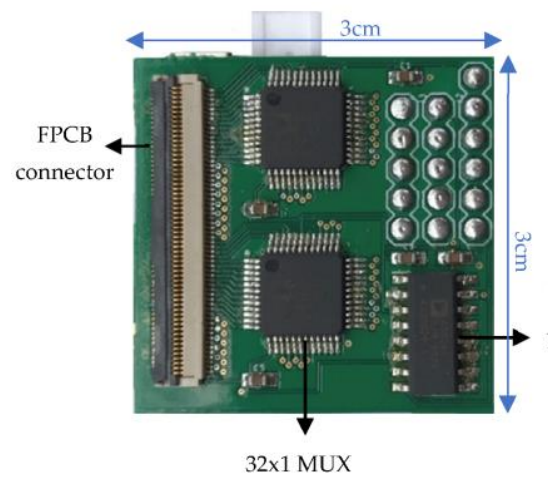

(a)

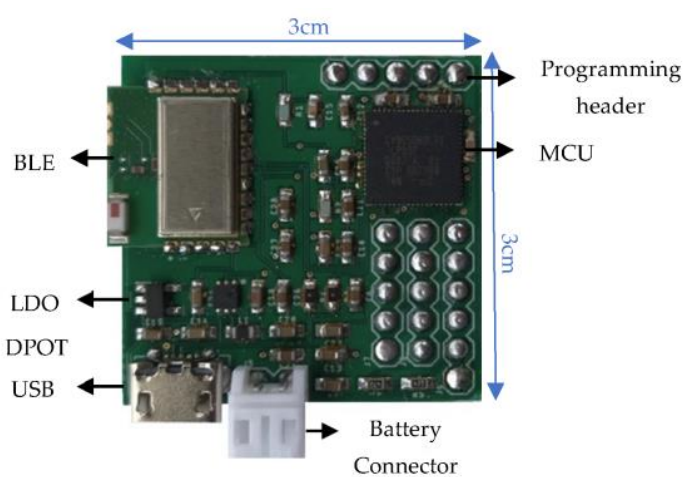

(b)

Figure 3. (a) Assembled top printed circuit board (PCB) with labelled parts $(3 \mathrm{~cm} \times 3 \mathrm{~cm} \times 0.2 \mathrm{~mm})$; (b) assembled bottom PCB with labelled parts $(3 \mathrm{~cm} \times 3 \mathrm{~cm} \times 0.2 \mathrm{~mm})$.

\subsection{Firmware and Algorithm}

To develop the firmware for the readout board, the following subsystems of PSoC5LP were utilized, as shown in Figure 4:

- $\quad A n \mathrm{I}^{2} \mathrm{C}$ block to communicate with the DPOT;

- A 16-bit Delta-Sigma ADC;

- Control registers to control the selection bits of $32 \times 1$ MUX;

- $2 \times 1$ analog MUX to combine the two $32 \times 1$ MUX outputs;

- A USB block to control the USB2.0 bus;

- A UART block to communicate with the BLE unit;

- A voltage digital-to-analog converter (VDAC) block to adjust the voltage of signals for UART transmit (TX) and receive (RX) lines.

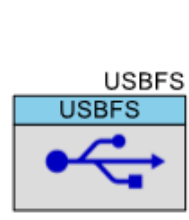

Control_Reg_1
\begin{tabular}{|r|l|}
\hline Control Reg & \\
\cline { 1 - 2 } control_0 & mux1_a0 \\
control_1 & mux1_a1 \\
control_2 & control_3 \\
control_4 & mux1_a2 \\
con mux1_a3 & mux1_a4
\end{tabular}
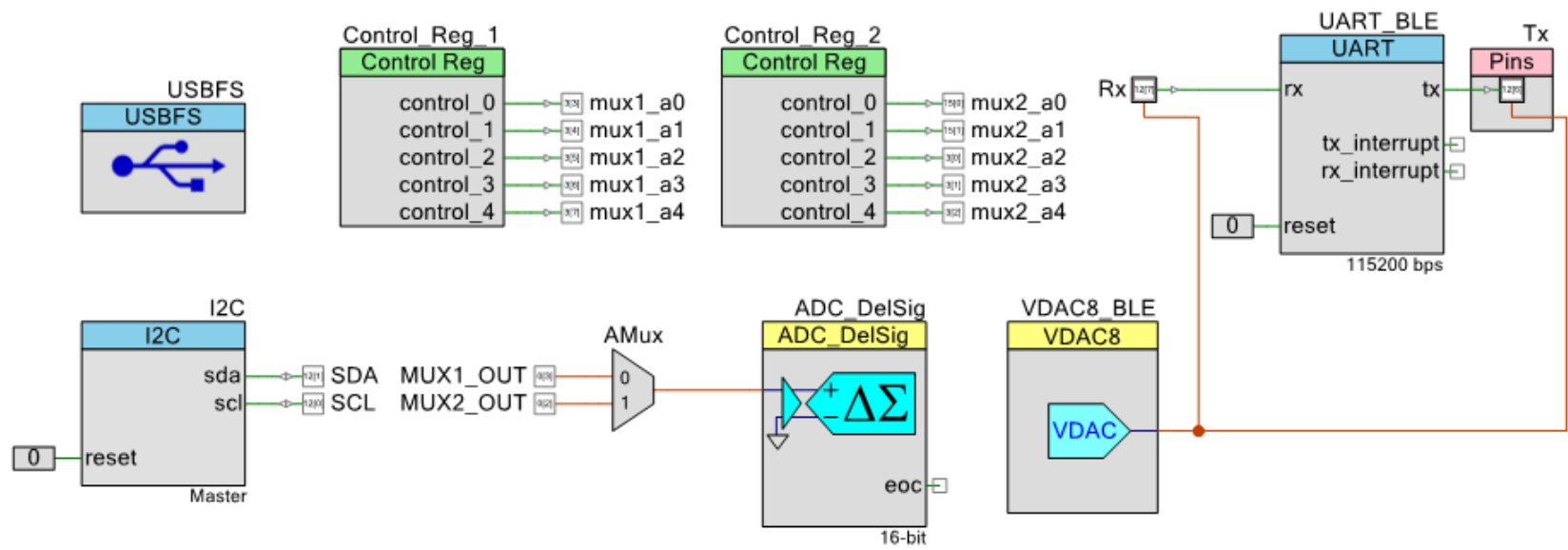

Figure 4. System firmware architecture in the programmable system-on-chip (PSoC) creator.

The source code was written in the embedded $\mathrm{C}$ programming language and was compiled using a "PSoC Creator 4.2" compiler released by Cypress semiconductors. A "CY8CKIT-002 PSoC MiniProg3 Program \& Debug Kit" (Cypress Semiconductor, San Jose, USA) was utilized to test and debug the board functionalities through Serial Wire Debug (SWD).

The flow chart of the proposed system is presented in Figure 5. After the system initialization was completed, a supply voltage was applied to the sensors. The finalized $R_{\text {sensor }}$ was obtained after tuning the $R_{r e f}$ to match the value of $R_{\text {sensor }}$. A few steps were required in the firmware to achieve tuned $R_{r e f}$. First, the value of $R_{r e f}$ was set to mid-range $\left(R_{\text {mid }}\right)$, and $A D C_{\text {voltage }}$ was obtained. Using the $A D C_{\text {voltage }}$ and Equation (2), the value of $R_{\text {sensor }}$ was calculated. During the next step, the value of $R_{r e f}$ was set to the computed 
value of $R_{\text {sensor }}$ in the previous step. Thus, the process automatically balanced the value of $R_{r e f}$ to $R_{\text {sensor }}$ and avoid the voltage saturation problem caused by the fixed $R_{r e f}$, which resulted in accurate $R_{\text {sensor }}$ values. The 60 sensors were measured one after the other in series, and equating $R_{r e f}$ to $R_{\text {sensor }}$ was performed every time before reading each sensor, using the firmware coding. Thus, the process was repeated 60 times until all the sensor values were calculated, and the obtained sensor data $\left(R_{\text {sensor }}\right)$ were transferred to a PC via USB or a smartphone via BLE.

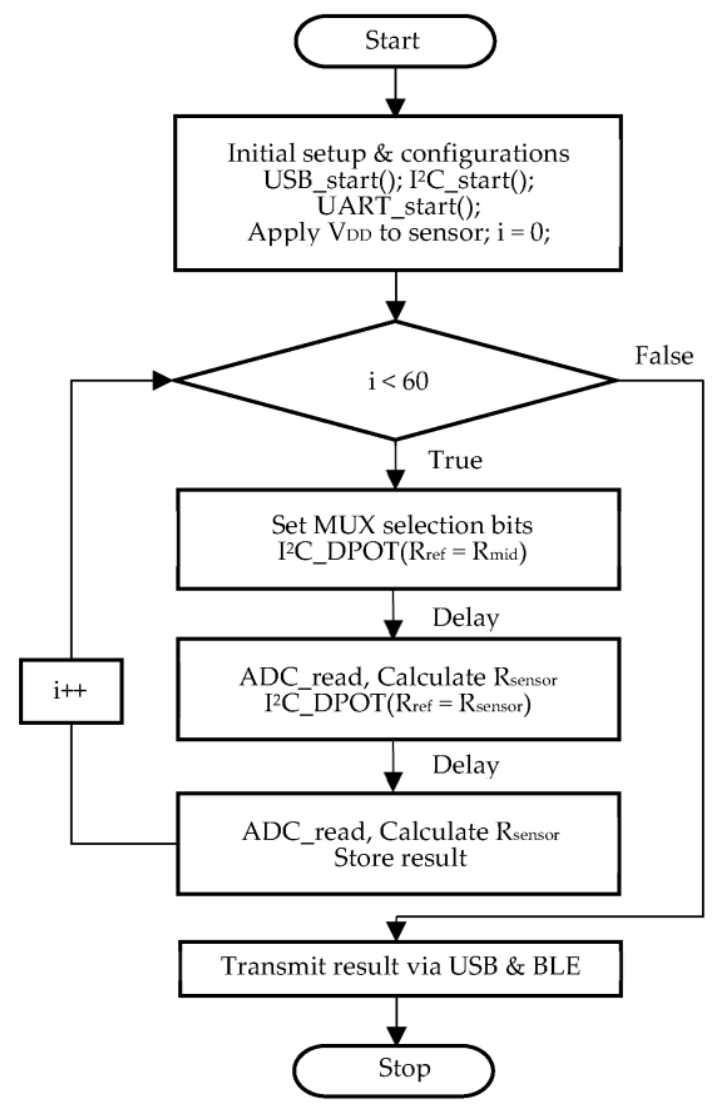

Figure 5. Flowchart of the proposed system.

\subsection{User Interface: GUI and Smartphone Application}

A customized GUI was developed to connect the readout board and the PC using a USB Communication Port (COM port). The GUI written in Python provided a realtime display plot to visualize the captured sensor data from the device and saved the obtained sensor data in a Comma Separated Values (CSV) format file. The "Tkinter" GUI framework and the "matplotlib" library were utilized to build the mentioned functionalities. Meanwhile, the USB communication was established using the "pySerial" library, and all the libraries were compiled into a single executable file using the "pyinstaller" library.

Figure 6 illustrates the sensor setting window and the experiment window of the customized GUI. The sensor setting window of the GUI consisted of 60 checkboxes to individually select/unselect a sensor and a connectivity check button. If the device was connected successfully, the button would turn green and showed "Connected"; otherwise, it showed "Disconnected" in red. The experiment window allowed the user to set the target experiment duration, perform sensor calibration, visualize the resistor values in a graph, select the $X$-axis to linear or log scale and start/stop the experiment. 


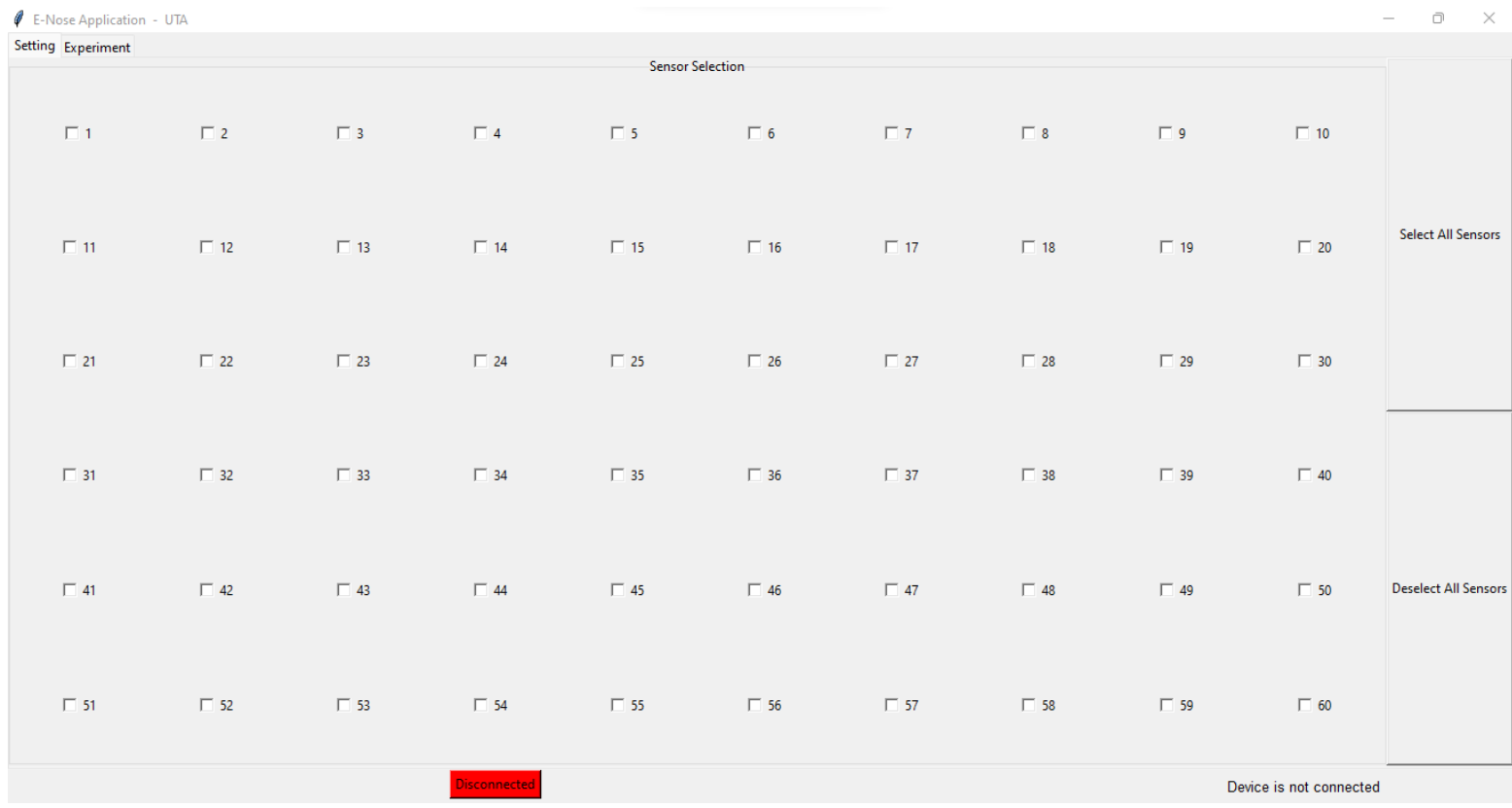

(a)
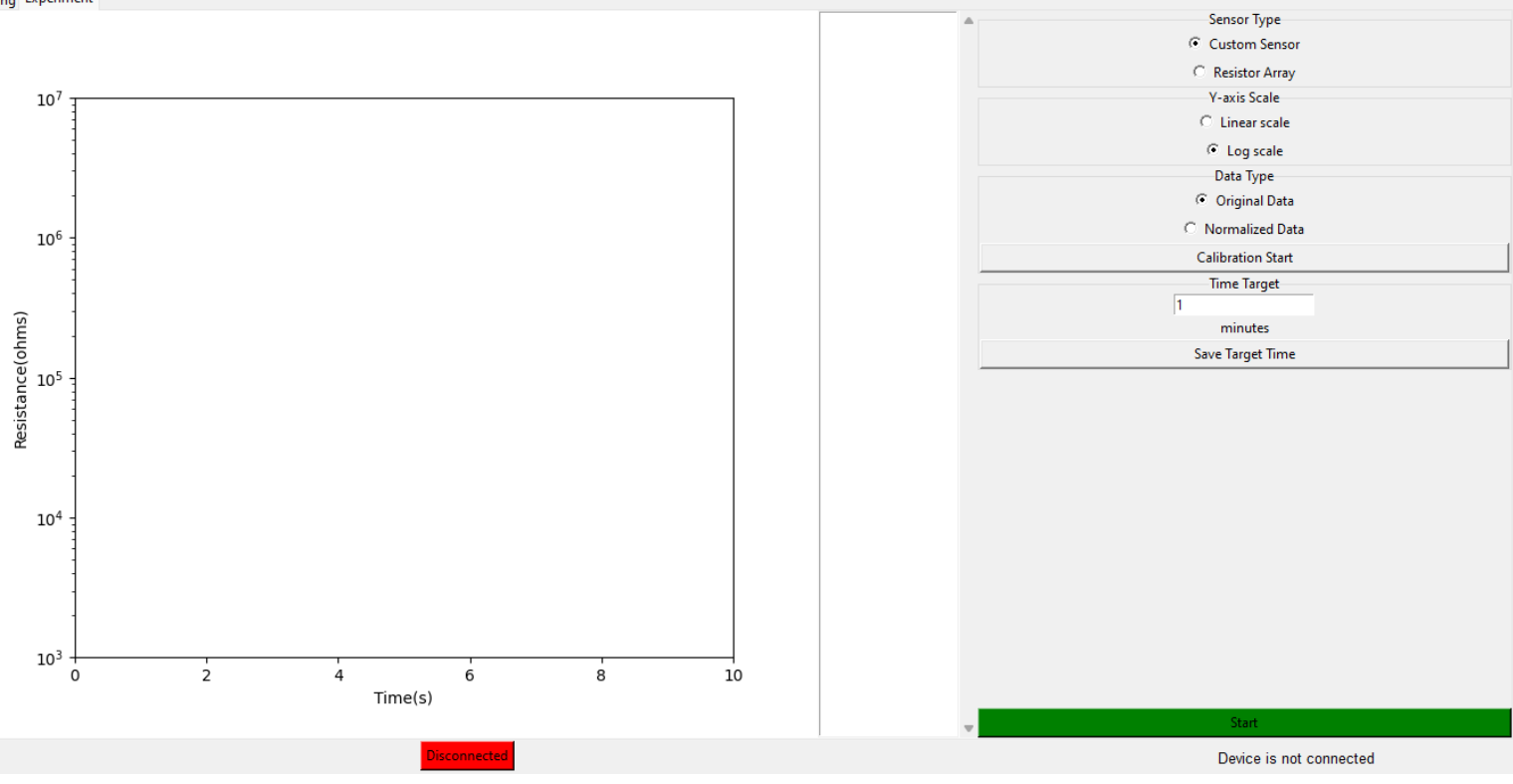

(b)

Device is not connected

Figure 6. (a) Sensor setting window of the graphical user interface (GUI); (b) experiment window of the GUI.

Meantime, the user can also use a smartphone application as a user interface to receive the data from the readout board. The "BLE Scanner" application (Bluepixel Technologies LLP, Ahmedabad, India) was used as a prototype to display the raw resistance values of the sensors, which were transmitted by the BLE unit in the board. The SPBTLE-1S BLE module was compliant with Bluetooth ${ }^{\circledR}$ specifications v4.2 with an embedded ceramic antenna that operated at $2.4 \mathrm{GHz}$. The device was recognizable with the name "BlueNRG-1" in the "BLE Scanner" application to connect with the readout board. Once the connection was made, communication could occur between the readout board and the smartphone through BLE. 


\section{Results}

3.1. Case Analysis 1: Test Setup with a Discrete Resistor Array and Electrical Testing Results

The proposed system was tested electrically for verification, and Figure 7a illustrates the test setup. To mimic the 60-sensor array, an electrical equivalent model with a 60-resistor array was fabricated on a PCB, as shown in Figure $7 \mathrm{~b}$. The 60-resistor array was realized by $0.1 \%$-tolerance thin-film discrete resistors, where the resistance varied from $1 \mathrm{~K} \Omega$ to $1 \mathrm{M} \Omega$. The resistor array was connected to the readout board using an FPCB jumper cable. The USB cable connected the readout board and the customized PC GUI to power up the board. In the GUI, the resistance values of 60 sensors were displayed (Figure 7c), which varied with respect to time, and the results were saved in the CSV format file to record the sensor response. Figure $7 \mathrm{~d}$ shows the system response displayed in the smartphone.

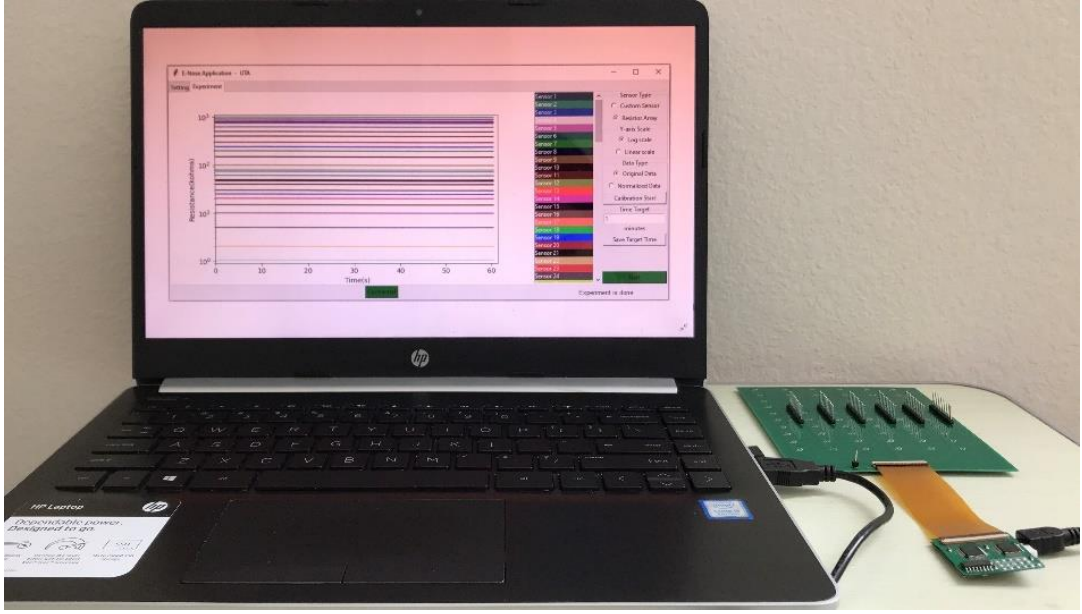

(a)

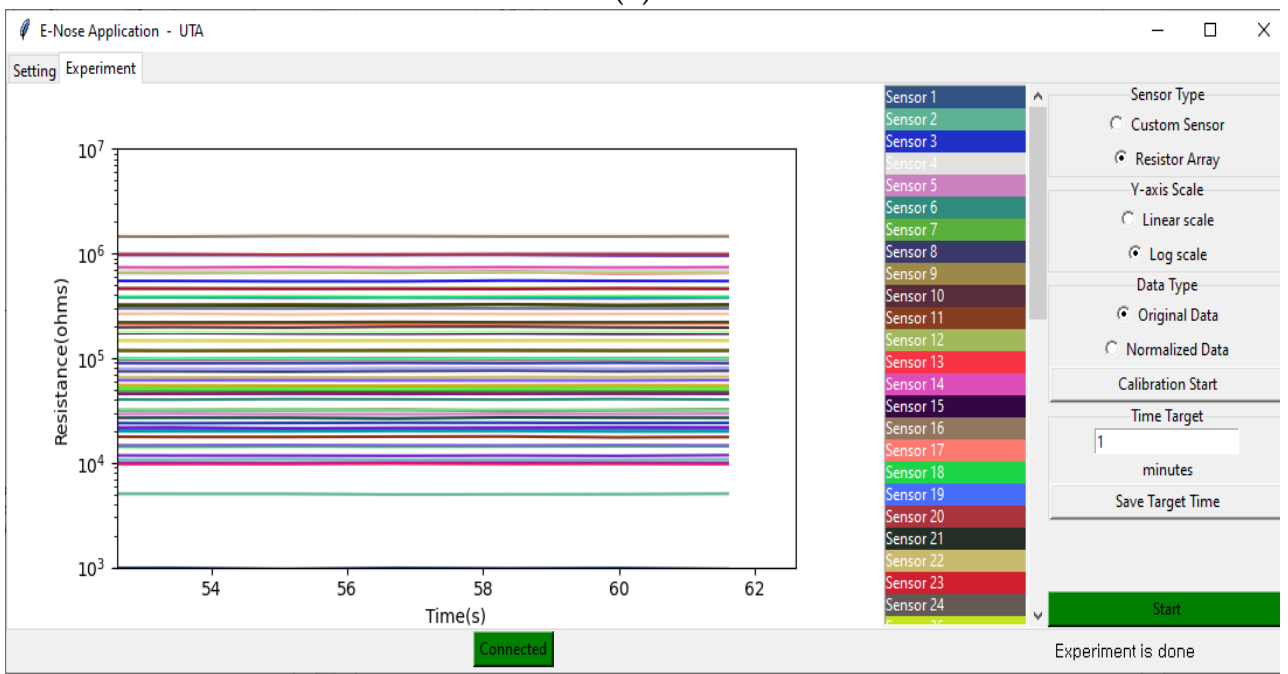

(c)

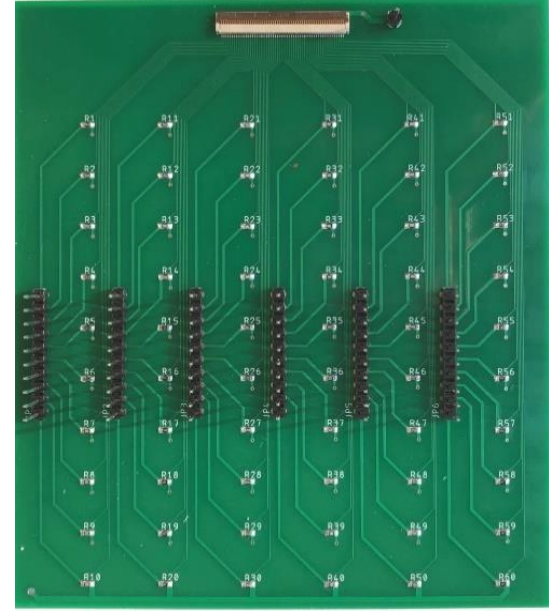

(b)

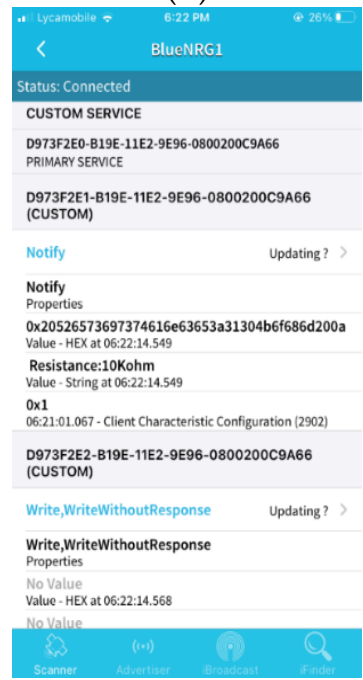

(d)

Figure 7. (a) Test setup with the readout board and the 60-resistor array; (b) 60-resistor array; (c) 60 resistor results displayed in the GUI; (d) system response displayed in a smartphone.

To validate the error rate of the proposed system, Equations (3)-(5) were utilized:

$$
\operatorname{Error}_{(a v g)}(\%)=\frac{R_{\text {exp }}-R_{\text {meas }(a v g)}}{R_{\text {exp }}} \times 100 \text {, }
$$




$$
\begin{aligned}
& \operatorname{Error}_{(\text {max })}(\%)=\frac{R_{\text {exp }}-R_{\text {meas }(\text { max })}}{R_{\text {exp }}} \times 100, \\
& \text { Error }_{(\text {min })}(\%)=\frac{R_{\text {exp }}-R_{\text {meas }(\text { min })}}{R_{\text {exp }}} \times 100,
\end{aligned}
$$

where $R_{\text {exp }}$ is the expected sensor resistance value measured using a digital multimeter "Agilent 34401A" (Keysight Technologies, Santa Rosa, USA) and $R_{\text {meas }}$ is the measured sensor resistance value obtained using the proposed readout board. In a span of $60 \mathrm{~s}$ ( $1 \mathrm{~min}$ ), 60 sensor data were collected 51 times, resulting in 3060 sensor samples. These samples were used to calculate the error rates as per Equations (3)-(5). The maximum, minimum, and average values of the measured sensors resistances and the corresponding values of error rates are listed in Table 3 . The sensor response $R_{\exp }$ versus $R_{\text {meas }(a v g)}$ showed a linear trend over the target measurement range, as depicted in Figure 8. The worst-case error rate reported during the experiment was under $2.5 \%$. Since it was tedious to display the system's transient response for all 60 values of the sensors, the transient response is illustrated for a span of one minute in Figure 9, with only six different sensor resistances, which were $1 \mathrm{M} \Omega, 750 \mathrm{~K} \Omega, 500 \mathrm{~K} \Omega, 100 \mathrm{~K} \Omega, 50 \mathrm{~K} \Omega$, and $10 \mathrm{~K} \Omega$.

Table 3. Sixty sensor readings—expected versus measured sensor resistances.

\begin{tabular}{lccccccc}
\hline Sensor & $\boldsymbol{R}_{\text {exp }}(\boldsymbol{\Omega})$ & $\boldsymbol{R}_{\text {meas }(\text { avg })}(\boldsymbol{\Omega})$ & $\boldsymbol{R}_{\text {meas }(\max )}(\boldsymbol{\Omega})$ & $\boldsymbol{R}_{\text {meas }(\min )}(\boldsymbol{\Omega})$ & Error $_{(\text {avg })}(\%)$ & Error $_{(\max )}(\%)$ & Error $_{(\min )}(\%)$ \\
\hline R1-R5 & $1,000,000$ & $1,009,537.00$ & $1,024,401.20$ & $997,827.65$ & -0.95 & -2.44 & 0.22 \\
R6-R10 & 800,000 & $811,997.40$ & $818,773.68$ & $800,976.85$ & -1.50 & -2.35 & -0.12 \\
R11-R15 & 750,000 & $754,240.60$ & $765,247.17$ & $743,990.80$ & -0.57 & -2.03 & 0.80 \\
R16-R20 & 500,000 & $504,167.20$ & $511,015.70$ & $498,515.00$ & -0.83 & -2.20 & 0.30 \\
R21-R25 & 300,000 & $301,481.70$ & $305,967.77$ & $298,185.59$ & -0.49 & -1.99 & 0.60 \\
R26-R30 & 205,000 & $205,518.40$ & $206,714.55$ & $200,183.09$ & -0.25 & -0.84 & 2.35 \\
R31-R35 & 100,000 & $100,021.60$ & $102,327.48$ & $99,236.38$ & -0.02 & -2.33 & 0.76 \\
R36-R40 & 75,000 & $75,192.49$ & $75,826.99$ & $74,634.44$ & -0.26 & -1.10 & 0.49 \\
R41-R45 & 50,000 & $50,574.35$ & $51,057.00$ & $49,858.35$ & -1.15 & -2.11 & 0.28 \\
R46-R50 & 30,000 & $30,729.80$ & $30,745.39$ & $29,690.22$ & -2.43 & -2.48 & 1.03 \\
R51-R55 & 20,500 & $20,627.91$ & $20,882.63$ & $20,258.24$ & -0.62 & -1.87 & 1.18 \\
R56-R60 & 10,000 & $10,045.01$ & $10,149.11$ & 9971.02 & -0.45 & -1.49 & 0.29 \\
\hline
\end{tabular}

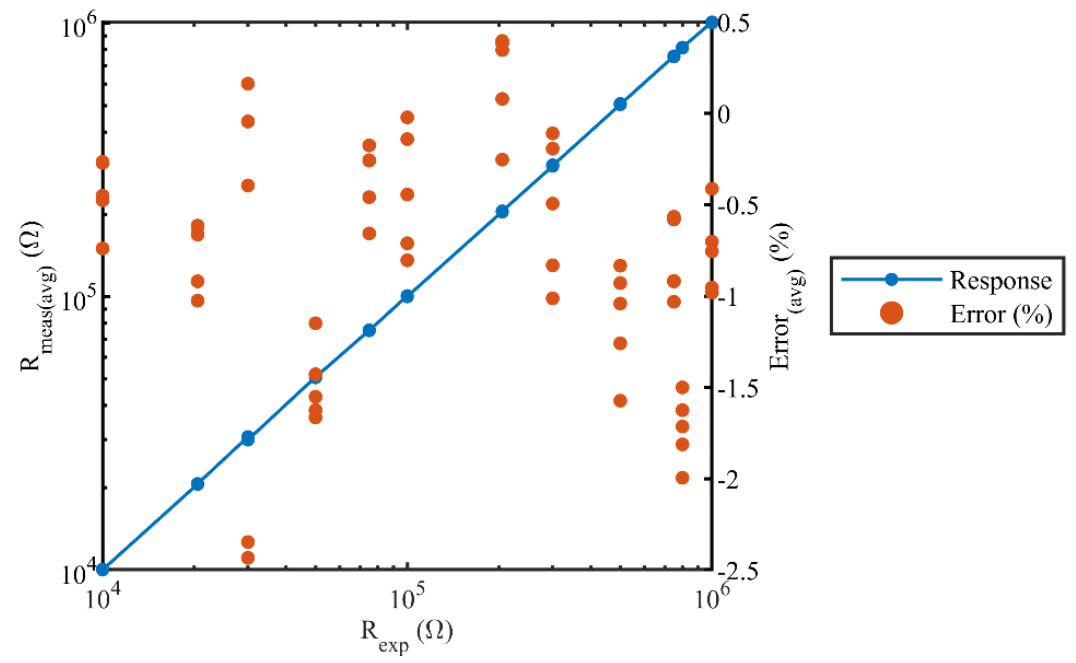

Figure 8. System response depicting the expected versus measured resistances and the average errors. 


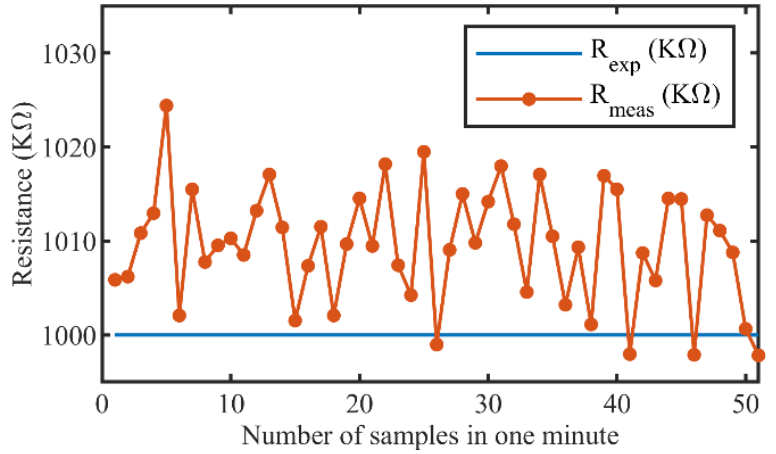

(a)

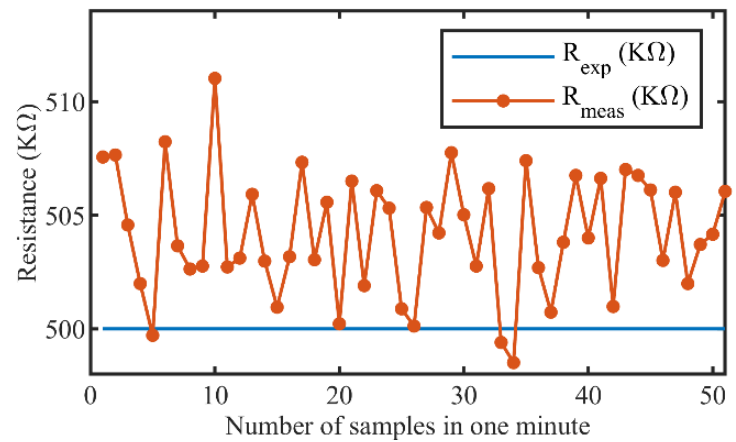

(c)

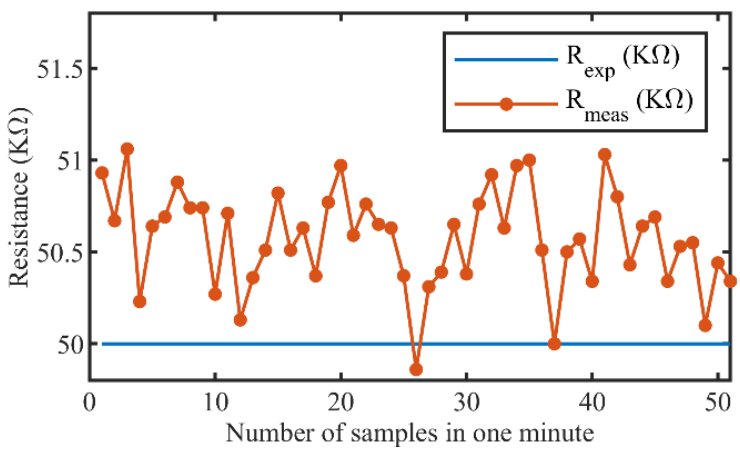

(e)

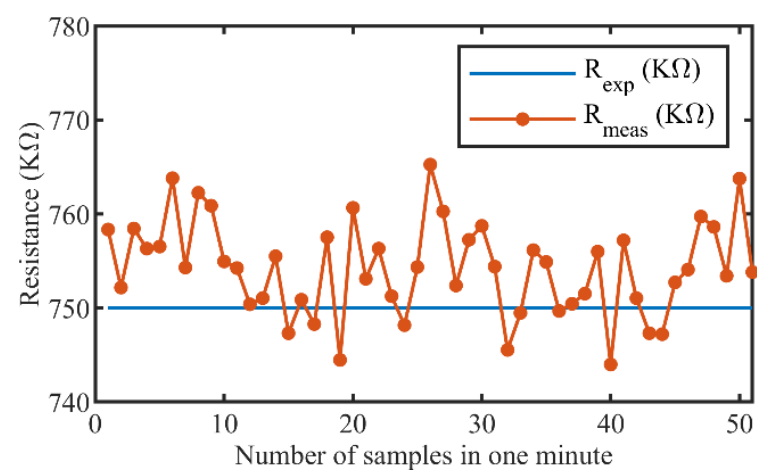

(b)

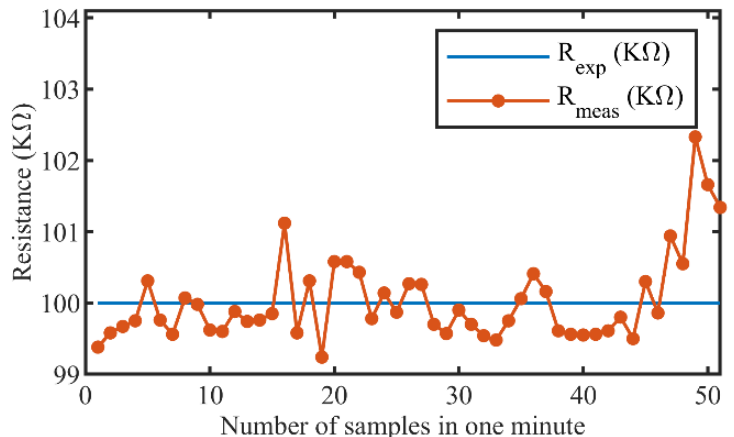

(d)

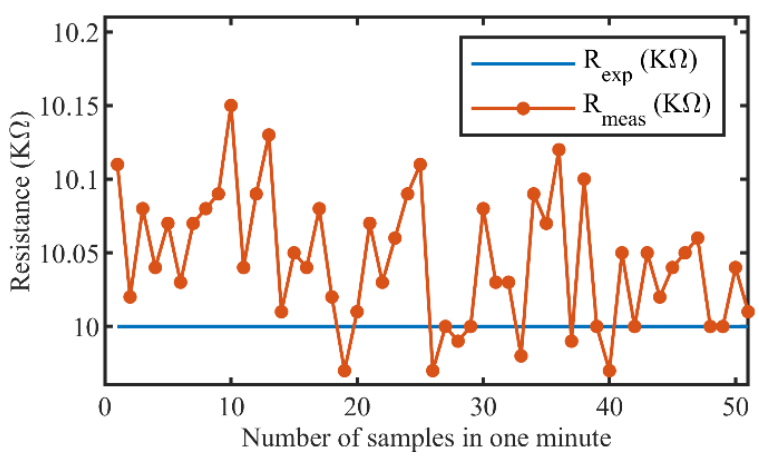

(f)

Figure 9. System's transient response: (a) $R_{\exp }=1 \mathrm{M} \Omega$; (b) $R_{\exp }=750 \mathrm{~K} \Omega$; (c) $R_{\exp }=500 \mathrm{~K} \Omega$; (d) $R_{\exp }=100 \mathrm{~K} \Omega ;(\mathbf{e}) R_{\exp }=50 \mathrm{~K} \Omega ;(\mathbf{f}) R_{\exp }=10 \mathrm{~K} \Omega$.

\subsection{Case Analysis 2: Test Setup with a Force-Sensitive Resistor and Sensor Testing Results}

As the second case analysis, the developed system was tested by interfacing with a commercially available force-sensitive resistor "FSR-406" (Interlink Electronics ${ }^{\circledR}$, Camarillo, USA). The "FSR-406" varies its resistance, depending on the force applied to the sensing area. The non-actuated sensor resistance is larger than $1 \mathrm{M} \Omega$, and its resistance decreases exponentially as per the force applied on the sensing area. The sensor had a sensing area of $0.75^{\prime \prime} \times 1.5^{\prime \prime}$ and can sense applied force in the range of $10 \mathrm{~g}$ to $10 \mathrm{Kg}$. During the experiment, "FSR-406" was connected to the readout board, as illustrated in Figure 10a, and the sensor response measured by the readout board $\left(R_{\text {board }}\right)$ was recorded throughout the applied weight range from $50 \mathrm{~g}$ to $750 \mathrm{~g}$. Simultaneously, the sensor response measured by a digital multimeter $\left(R_{d m}\right)$ was also captured using the digital multimeter "Agilent 34401A" (Keysight Technologies, Santa Rosa, USA). Ten readings were taken and averaged to obtain both $R_{\text {board }}$ and $R_{d m}$. The comparison results between $R_{\text {board }}, R_{d m}$, and the corresponding error rates calculated during the experiment are listed in Table 4 . The response of the designed readout board showed a close correlation with the response measured using a digital multimeter, demonstrating a satisfactory performance as illustrated in Figure 10b. Due 
to the unstable response of "FSR-406" at lower weights, the experiments were conducted for weights of $50 \mathrm{~g}$ and above to avoid inaccurate results.

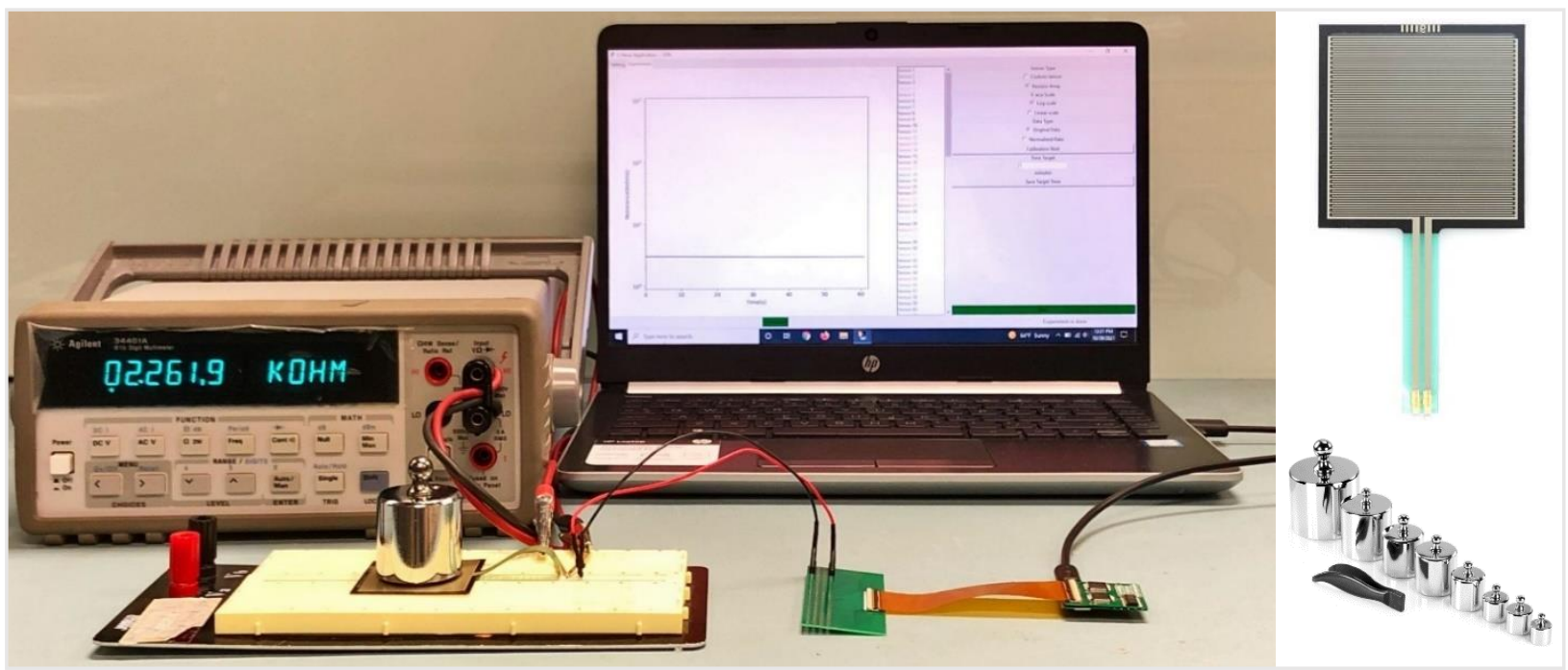

(a)

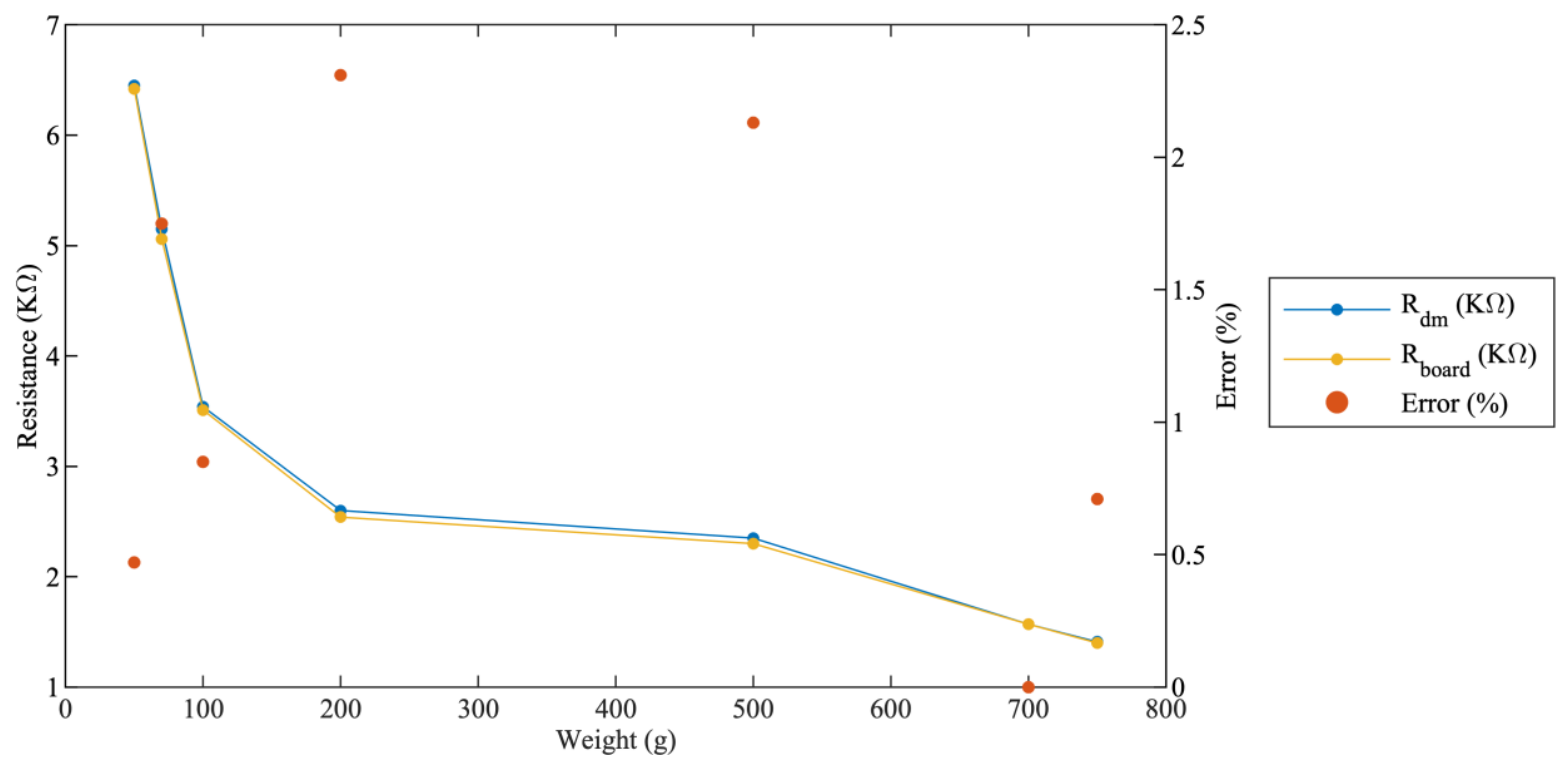

(b)

Figure 10. (a) Test setup with the readout board, "FSR-406", and weights; (b) comparison of the "FSR-406" responses using a digital multimeter and the readout board.

Table 4. Results of the readout board with "FSR-406" for the weight range of 50-750 g.

\begin{tabular}{cccc}
\hline Weight $(\mathrm{g})$ & $\boldsymbol{R}_{\boldsymbol{d m}}(\mathbf{K} \Omega)$ & $\boldsymbol{R}_{\text {board }}(\mathbf{K} \Omega)$ & Error $(\%)$ \\
\hline 50 & 6.45 & 6.42 & 0.47 \\
70 & 5.15 & 5.06 & 1.75 \\
100 & 3.54 & 3.51 & 0.85 \\
200 & 2.60 & 2.54 & 2.31 \\
500 & 2.35 & 2.30 & 2.13 \\
700 & 1.57 & 1.57 & 0.00 \\
750 & 1.41 & 1.40 & 0.71 \\
\hline
\end{tabular}




\section{Discussion and Conclusions}

The overall system performance is summarized in Table 5. In a span of $60 \mathrm{~s}$ (1 min), 60 sensor readings were collected and stored in the CSV file 51 times, resulting in a total of 3060 sensor measurements. This led to a processing speed of $51 \mathrm{~Hz}$, equivalent to $19.6 \mathrm{~ms}$, to collect, process and transmit the data from a single sensor to the GUI. The processing speed often depends on the input resistance range. Thus, the system targeting solely piezoresistive sensors provided a somewhat faster response due to the lower target resistance. However, typical e-nose gas detection systems, which target chemiresistive sensors of a wide range up to $1 \mathrm{M} \Omega$, offer a processing speed of $0.1 \mathrm{~Hz}$ to $10 \mathrm{~Hz}$ (10 s to $100 \mathrm{~ms}$ per sensor) [33]. Compared with those systems, the proposed method provides a processing speed of $51 \mathrm{~Hz}$ (19.6 ms per sensor), which is significantly faster. Also, an application such as a comprehensive breathing analyzer requires a sampling frequency range of $0.1 \mathrm{~Hz}$ to $0.8 \mathrm{~Hz}$ [5], which can be easily satisfied by the proposed system. The readout system achieved a worst-case error rate of less than $2.5 \%$. These variations were caused by the combination of the supply voltage fluctuation of regulators by $\pm 2 \%$, the DPOT error rate of \pm 0.5 least significant bit (LSB), the $0.1 \%$ tolerance of thin-film discrete resistors in the resistor array, and the ADC conversion error. The system power consumption was around $95 \mathrm{~mW}$, and the majority of the power was consumed while the BLE was transmitting the data to the user. The low-power-consumption profile makes the device suitable for battery-powered wireless sensor networks.

Table 5. System performance summary.

\begin{tabular}{ll}
\hline Measurable resistance range & $1 \mathrm{~K} \Omega-1 \mathrm{M} \Omega$ \\
\hline Error rate & $0-2.5 \%$ \\
Number of sensors & $60 ;$ can be expandable \\
Device dimension & $3 \mathrm{~cm} \times 3 \mathrm{~cm}$ \\
Supply voltage & $5 \mathrm{~V}$ \\
System power consumption & $\sim 95 \mathrm{~mW}$ at $5 \mathrm{~V}$ \\
Processing speed/data rate & $51 \mathrm{~Hz}$ \\
ADC resolution & $16 \mathrm{bits}$ \\
Approximate system cost & $\$ 100$ \\
\hline
\end{tabular}

The possible limitation of the system can be its scalability to adopt a more extensive size array. The expansion of the system to more than 60 sensors makes the system bulkier and might not be appropriate for wearable electronics. As future work, the prototype will be tested chemically by interfacing with chemiresistive gas sensors to detect the target analytes of various concentrations.

To summarize, a compact universal-type resistive sensor array readout based on the $\mathrm{R}-\mathrm{V}$ conversion is presented. This work demonstrates the novelty and potential application of an integrated wearable sensing system with the following attributes: a low-cost system with a wireless communication capability, a facility to accommodate a high-density resistive sensor array, and portable readout electronics with a small form factor of $3 \mathrm{~cm} \times 3 \mathrm{~cm}$. The system behaves as an electrophysiological sensing interface for wearable healthcare monitoring systems, supporting multi-functionality hybrid sensing, and can be implemented as a readout for e-skin or e-nose. These advantages, especially low-cost, small size, and low power consumption, allow the device to be utilized in battery-powered wireless sensor network applications and next-generation self-sustainable integrated wearable systems in the IoT era.

Author Contributions: Conceptualization, S.J., S.L. and H.P.; methodology, S.L.; software, Y.P.; validation, Y.P., S.L. and H.P.; formal analysis, H.P.; investigation, S.L. and Y.P.; resources, S.J.; data curation, Y.P.; writing—original draft preparation, S.L.; writing—review and editing, H.P., S.J. and Y.P.; visualization, S.J.; supervision, S.J.; project administration, S.J.; funding acquisition, S.J. All authors have read and agreed to the published version of the manuscript. 
Funding: This research received no external funding.

Institutional Review Board Statement: Not applicable.

Informed Consent Statement: Not applicable.

Data Availability Statement: The datasets generated from the current study are available from the corresponding author on reasonable request.

Conflicts of Interest: The authors declare no conflict of interest.

\section{References}

1. Rodrigues, J.J.; Segundo, D.B.D.R.; Junqueira, H.A.; Sabino, M.H.; Prince, R.M.; Al-Muhtadi, J.; De Albuquerque, V.H.C. Enabling Technologies for the Internet of Health Things. IEEE Access 2018, 6, 13129-13141. [CrossRef]

2. Tao, X.M.; Feng, D.D. A Wearable, Wireless Electronic Interface for Textile Sensors Lin Shu. In Proceedings of the 2010 IEEE International Symposium on Circuits and Systems, Paris, France, 30 May-2 June 2010; pp. 3104-3107.

3. Alexandre, R.; Postolache, O. Wearable and IoT Technologies Application for Physical Rehabilitation. In Proceedings of the 2018 International Symposium in Sensing and Instrumentation in IoT Era (ISSI), Shanghai, China, 6-7 September 2018; pp. 1-6.

4. Cheng, Y.; Wang, K.; Xu, H.; Li, T.; Jin, Q.; Cui, D. Recent developments in sensors for wearable device applications. Anal. Bioanal. Chem. 2021, 413, 6037-6057. [CrossRef] [PubMed]

5. Paolini, G.; Shanawani, M.; Masotti, D.; Schreurs, D.M.M.-P.; Costanzo, A. Respiratory activity monitoring by a wearable 5.8 GHz SILO with energy harvesting capabilities. IEEE J. Electromagn. RF Microw. Med. Biol. 2021, 1-7. [CrossRef]

6. Lou, Z.; Wang, L.; Jiang, K.; Wei, Z.; Shen, G. Reviews of Wearable Healthcare Systems: Materials, Devices and System Integration. Mater. Sci. Eng. R Rep. 2020, 140, 100523. [CrossRef]

7. Xu, C.; Yang, Y.; Gao, W. Skin-Interfaced Sensors in Digital Medicine: From Materials to Applications. Matter 2020, 2, 1414-1445. [CrossRef]

8. Duan, L.; D’hooge, D.R.; Cardon, L. Recent Progress on Flexible and Stretchable Piezoresistive Strain Sensors: From Design to Application. Prog. Mater. Sci. 2020, 114, 100617. [CrossRef]

9. $\quad$ Lee, K.; Chae, H.Y.; Park, K.; Lee, Y.; Cho, S.; Ko, H.; Kim, J.J. A Multi-Functional Physiological Hybrid-Sensing E-Skin Integrated Interface for Wearable IoT Applications. IEEE Trans. Biomed. Circuits Syst. 2019, 13, 1535-1544. [CrossRef]

10. Lugoda, P.; Costa, J.C.; Pouryazdan, A.; Garcia-Garcia, L.A.; Roggen, D.; Munzenrieder, N. Evaluation of a pseudo zero-potential flexible readout circuit for resistive sensor matrixes. In Proceedings of the 2020 IEEE International Conference on Flexible and Printable Sensors and Systems (FLEPS), Manchester, UK, 16-19 August 2020; pp. 1-4.

11. Shu, L.; Tao, X.; Feng, D.D. A New Approach for Readout of Resistive Sensor Arrays for Wearable Electronic Applications. IEEE Sens. J. 2015, 15, 442-452.

12. OQuigley, C.; Sabourin, M.; Coyle, S.; Connolly, J.; Condall, J.; Curran, K.; Corcoran, B.; Diamond, D. Characteristics of a Piezo-Resistive Fabric Stretch Sensor Glove for Home-Monitoring of Rheumatoid Arthritis. In Proceedings of the 2014 11th International Conference on Wearable and Implantable Body Sensor Networks Workshops, Zurich, Switzerland, 16-19 June 2014; pp. 23-26.

13. Matsuda, R.; Mizuguchi, S.; Nakamura, F.; Endo, T.; Isoda, Y.; Inamori, G.; Ota, H. Highly Stretchable Sensing Array for Independent Detection of Pressure and Strain Exploiting Structural and Resistive Control. Sci. Rep. 2020, 10, 12666. [CrossRef]

14. Alaferdov, A.V.; Savu, R.; Rackauskas, S.; Rackauskas, T.; Canesqui, M.A.; Moshkalev, S.A. Graphene Nanobelts Films for Highly Sensitive, Transparent and Flexible Pressure and Strain Resistive Sensors. In Proceedings of the 2014 IEEE 2nd International Conference on Emerging Electronics (ICEE), Bengaluru, India, 3-6 December 2014; pp. 1-4.

15. Chen, Y.; Liang, X.; Assaad, M.; Heidari, H. Wearable Resistive-Based Gesture-Sensing Interface Bracelet. In Proceedings of the 2019 UK/China Emerging Technologies (UCET), Glasgow, UK, 21-22 August 2019; pp. 1-4.

16. Wen, F.; He, T.; Liu, H.; Chen, H.-Y.; Zhang, T.; Lee, C. Advances in Chemical Sensing Technology for Enabling the Next-Generation Self-Sustainable Integrated Wearable System in the IoT Era. Nano Energy 2020, 78, 105155. [CrossRef]

17. Karakaya, D.; Ulucan, O.; Turkan, M. Electronic nose and its applications: A survey. Int. J. Autom. Comput. 2020, 17, 179-209. [CrossRef]

18. Wu, Z.; Zhang, H.; Sun, W.; Lu, N.; Yan, M.; Wu, Y.; Hua, Z.; Fan, S. Development of a low-cost portable electronic nose for cigarette brands identification. Sensors 2020, 20, 4239. [CrossRef] [PubMed]

19. Ye, Z.; Liu, Y.; Li, Q. Recent progress in smart electronic nose technologies enabled with machine learning methods. Sensors 2021, 21, 7620. [CrossRef] [PubMed]

20. Cao, X.; Chen, H.; Gu, X.; Liu, B.; Wang, W.; Cao, Y.; Wu, F.; Zhou, C. Screen Printing as a Scalable and Low-Cost Approach for Rigid and Flexible Thin-Film Transistors Using Separated Carbon Nanotubes. ACS Nano 2014, 8, 12769-12776. [CrossRef] [PubMed]

21. Pandhi, T.; Chandnani, A.; Subbaraman, H.; Estrada, D. A Review of Inkjet Printed Graphene and Carbon Nanotubes Based Gas Sensors. Sensors 2020, 20, 5642. [CrossRef]

22. Hartwig, M.; Zichner, R.; Joseph, Y. Inkjet-Printed Wireless Chemiresistive Sensors-A Review. Chemosensors 2018, 6, 66. [CrossRef] 
23. Chiu, S.-W.; Tang, K.-T. Towards a Chemiresistive Sensor-Integrated Electronic Nose: A Review. Sensors 2013, 13, 14214-14247. [CrossRef]

24. Joshi, N.; Hayasaka, T.; Liu, Y.; Liu, H.; Oliveira, O.N., Jr.; Lin, L. A Review on Chemiresistive Room Temperature Gas Sensors Based on Metal Oxide Nanostructures, Graphene and 2D Transition Metal Dichalcogenides. Mikrochim. Acta 2018, $185,213$. [CrossRef]

25. Jian, Y.; Hu, W.; Zhao, Z.; Cheng, P.; Haick, H.; Yao, M.; Wu, W. Gas Sensors Based on Chemi-Resistive Hybrid Functional Nanomaterials. Nanomicro Lett. 2020, 12, 71. [CrossRef]

26. Tien, N.T.; Jeon, S.; Kim, D.-I.; Trung, T.Q.; Jang, M.; Hwang, B.-U.; Byun, K.-E.; Bae, J.; Lee, E.; Tok, J.B.-H.; et al. A Flexible Bimodal Sensor Array for Simultaneous Sensing of Pressure and Temperature. Adv. Mater. 2014, 26, 796-804. [CrossRef]

27. Parikesit, E.; Mengko, T.L.R.; Zakaria, H. Wearable Gait Measurement System Based on Accelerometer and Pressure Sensor. In Proceedings of the 2011 2nd International Conference on Instrumentation, Communications, Information Technology, and Biomedical Engineering, Bandung, Indonesia, 8-9 November 2011; pp. 395-398.

28. Zhou, Y.; Desplenter, T.; Chinchalkar, S.; Trejos, A.L. A Wearable Mechatronic Glove for Resistive Hand Therapy Exercises. In Proceedings of the 2019 IEEE 16th International Conference on Rehabilitation Robotics (ICORR), Toronto, ON, Canada, 24-28 June 2019; pp. 1097-1102.

29. Tsao, L.-C.; Cheng, M.-Y.; Chen, I.-L.; Shih, W.-P.; Yang, Y.-J.; Chang, F.-Y.; Fan, K.-C.; Chang, S.-H. Flexible Temperature Sensor Array Using Electro-Resistive Polymer Forhumanoid Artificial Skin. In Proceedings of the TRANSDUCERS 2007-2007 International Solid-State Sensors, Actuators and Microsystems Conference, Lyon, France, 10-14 June 2007.

30. Lichtenwalner, D.J.; Hydrick, A.E.; Kingon, A.I. Flexible Thin Film Temperature and Strain Sensor Array Utilizing a Novel Sensing Concept. Sens. Actuators A Phys. 2007, 135, 593-597. [CrossRef]

31. Kassal, P.; Steinberg, M.D.; Steinberg, I.M. Wireless Chemical Sensors and Biosensors: A Review. Sens. Actuators B Chem. 2018, 266, 228-245. [CrossRef]

32. Chen, D.; Cai, Y.; Huang, M.-C. Customizable Pressure Sensor Array: Design and Evaluation. IEEE Sens. J. 2018, 18, 6337-6344. [CrossRef]

33. Wang, J.; Gu, W.; Qi, W.; Li, C.; Chen, D.; Adedokun, G.; Xu, L.; Wu, F. A fully integrated gas detection system with programmable heating voltage and digital output rate for gas sensor array. IEEE Sens. J. 2021, 21, 6821-6829. [CrossRef] 